\title{
Creating a safe sleep environment for babies: what are the practices performed by mothers?
}

\author{
Esin Zeren \\ Family Health Center, Gaziantep, Turkey, and \\ Ayșe Şener Taplak and Sevinç Polat \\ Yozgat Bozok University, Yozgat, Turkey
}

Received 30 April 2020 Revised 22 August 2020 10 November 2020

Accepted 17 November 2020

\begin{abstract}
Purpose - This study aims to determine the practices performed by mothers to create a safe sleep environment for their babies.

Design/methodology/approach - This cross-sectional study was conducted at Family Health Centers (FHCs), the Central Anatolian Region of Turkey. The study sample consisted of 455 mothers who had 0-12month-old babies. The data were collected via a questionnaire to ascertain the descriptive characteristics and means of creating a safe sleeping environment.

Findings - Mothers performed unsafe/risky practices as well as safe practices. Unsafe practices of mothers included $92.3 \%$ preferring soft mattresses, $87.0 \%$ placed a pillow under the baby's head, $17.8 \%$ preferred a prone sleep position for their baby, $16.9 \%$ covered the baby's face with a piece of thin cloth, $14.3 \%$ kept the sheet on the mattress loose, $6.8 \%$ of the mothers shared the same bed, $2.4 \%$ reported smoking in the environment where the baby slept.

Originality/value - Based on our findings, it is recommended that nurses should provide information on creating a safe sleep environment to mothers during $\mathrm{FHC}$ visits, and at-risk practices should be identified through home visits.
\end{abstract}

Keywords Safe sleep environment, Baby, Mothers, Practices Turkey

Paper type Research paper

\section{Introduction}

A large majority of infant deaths occur due to sudden unexpected infant deaths (SIDS), which generally occurs during sleep and mostly due to an unsuitable sleep environment, within the first year of life [1-3]. In the USA, nearly 3,500-4,000 babies die due to sleep-related SIDS each year [4-7]. The Center for Disease Prevention and Control reported that SIDS is among the top three causes of infant deaths, and in 2018, approximately 1,300 infant deaths occurred due to SIDS, 1,300 due to unknown causes and 800 due to accidental suffocation and strangulation in bed [8]. Data on the incidence of SIDS in Turkey are inadequate; however, the rate of sleep-related SIDS is reported to vary between 1.2 and $9.9 \%$ in studies conducted in different provinces [9-11].

As newborns and infants spend most of the day sleeping, creating a safe sleep environment for them is extremely important $[12,13]$. In line with studies on the subject, a safe

(C) Esin Zeren, Ayşe Şener Taplak and Sevinç Polat. Published in Journal of Health Research. Published by Emerald Publishing Limited. This article is published under the Creative Commons Attribution (CC BY 4.0) licence. Anyone may reproduce, distribute, translate and create derivative works of this article (for both commercial and non-commercial purposes), subject to full attribution to the original publication and authors. The full terms of this licence may be seen at http://creativecommons.org/licences/by/4.0/ legalcode

Funding: The authors received no financial support for the research, authorship and/or publication of this article. a safe sleep

environment 
JHR

36,2

324

sleep environment can be defined as the arrangement of the baby's sleep environment in such a way as to protect the baby from risky situations such as accidental suffocation or SIDS during sleep [14-16]. To create a safe sleep environment, the American Academy of Pediatrics (AAP) recommended that the baby should sleep in a supine position, using a firm sleeping surface, avoiding the use of a soft mattress, sharing a room with the baby without sharing the bed, keeping soft objects away from the cradle, using a pacifier during nap-time, avoiding an excessively warm environment, placing the baby in bed so that the baby's feet touch the bottom edge of the bed (mattress), keeping the sheet on the mattress tight and placing the blanket below the baby's armpits [16-18].

To prevent negative consequences during sleep, parents must assume important responsibilities to eliminate risk factors related to the sleep environment. As the primary responsibility for baby care lies with mothers, evaluating their awareness of safe sleep and risky behaviors is of great importance in terms of reducing sleep-related infant deaths and directing the healthcare professionals' educational activities regarding the issue $[5,16]$. This study aimed to determine the safe and unsafe practices performed by mothers and the effect of sociodemographic characteristics on mothers' unsafe practices.

\section{Methodology \\ Study design}

This cross-sectional study was conducted in family health centers (FHCs) in a city center in the Central Anatolian Region of Turkey between February and September 2017. FHCs are health institutions that are responsible for the provision of primary healthcare services, and within this context, preventive health services, primary care diagnosis, treatment, rehabilitation and consultancy services are performed in FHCs.

\section{Participants}

In the central district of the province, there are 11 FHCs. Of these, two were excluded from the study because they had only recently begun to provide health services, and thus, there were not many patients registered with them. Therefore, the study included nine FHCs.

Of the mothers who presented to the FHCs between the aforementioned dates, those who had 0-12-month-old babies, had no communication and language problems, had babies with no health problems requiring special care (e.g. chronic diseases or congenital anomalies) and agreed to participate were included in the study. The total sample size was 455 mothers, calculated using the power analysis of the Minitab program with a deviation rate of $5 \%$ and a confidence interval of $99 \%$.

\section{Data collection}

The descriptive characteristic questionnaire for the mother and baby and creating a safe sleeping environment questionnaire was used to collect the data.

Descriptive characteristic questionnaire for the mother and babies. The questionnaire consisted of items about the participating mothers' and babies' sociodemographic characteristics.

Creating a safe sleeping environment questionnaire. The researchers prepared this questionnaire by reviewing pertinent literature. It included questions on the practices performed by mothers to create a safe sleep environment, the properties of the materials they use in creating a safe sleep environment and the baby's sleeping position [1, 5, 15, 17-19]. 
Administration of the questionnaires

Personnel working in FHCs were informed about the purpose and scope of the research. The questionnaires were filled out in a room in the FHCs allocated for the interviews after the babies were examined. The interview rooms were free from interruptions and outside noise, which enabled the researchers to communicate with the participants comfortably. The data were collected using the descriptive characteristic questionnaire and creating a safe sleeping environment questionnaire. The questionnaires were completed face to face for an average of $20 \mathrm{~min}$.

\section{Ethical issues}

Before the study was conducted, necessary permissions were obtained from the Public Health Institution and Bozok University Non-invasive Clinical Research Ethics Committee (201702/03). Additionally, written consent of the mothers included in the study was obtained.

\section{Data analysis}

Data were analyzed using the IBM SPSS Statistics 25.0 (IBM Corp., New York, USA). Descriptive statistics were given in numbers $(n)$ and percentages $(\%)$. Binary logistic regression with backward elimination analysis was used to determine sociodemographic factors affecting mothers' unsafe practices. For all applications, age, educational status, economic status, family type, number of children and employment status were modeled. Factors with $p<0.10$ were included in the final model, and $p<0.05$ was considered statistically significant.

\section{Results}

About $47.9 \%$ were in the age group of $26-35$ years, and $39.5 \%$ were senior high-school graduates. Two-thirds of the mothers were housewifes and did not work, and the majority had a core family and defined their family's economic status as "income equal to expenses." Half of them had one child. Of the babies, $55.2 \%$ were females, $60.2 \%$ were delivered by natural childbirth and $53.2 \%$ were exclusively breastfed (Table 1 ).

\section{The safe and unsafe practices performed by mothers}

In Table 2, of the mothers, $95.4 \%$ shared the same room with their baby, $98.7 \%$ kept the temperature of the room where the baby slept at an appropriate level $\left(20-24{ }^{\circ} \mathrm{C}\right), 85.7 \%$ kept the sheet on the mattress tight, $36.9 \%$ preferred the supine sleep position for their baby and $3.3 \%$ swaddled their baby during sleep. Moreover, $83.1 \%$ did not cover the baby's face with a piece of thin cloth while the baby was asleep, $97.6 \%$ did not smoke, $13.0 \%$ did not use a pillow under the baby's head (safe practices). On the other hand, $92.3 \%$ of the mothers preferred soft sleep surface/mattress, $87.0 \%$ placed a pillow under the baby's head, $16.9 \%$ covered the baby's face with a piece of thin cloth while the baby was asleep, $14.3 \%$ kept the sheet on the mattress loose, $6.8 \%$ shared the same bed with the baby and $2.4 \%$ reported smoking in the environment where the baby slept (unsafe/risky practices).

\section{The sociodemographic characteristics affecting the mother's unsafe practices}

In Table 3, no statistically significant variable was found for the sleep surface/characteristic of the mattress used in the baby's cradle and the applications of using pacifiers during sleep. It has been determined that the mother's economic situation affects bed-sharing. Accordingly, the unsafe application rate of those whose income is less than their expenses is 5.129 times

\section{Creating \\ a safe sleep environment}


JHR

36,2

\begin{tabular}{lrrr}
\hline Characteristics & $n$ & & $\%$ \\
\hline Mothers' age (years) $(\bar{x} \pm \mathrm{SD})$ & & $28.3 \pm 6.4$ & \\
$16-25$ & 161 & & 35.4 \\
$26-35$ & 218 & & 47.9 \\
$36-44$ & 76 & & 16.7
\end{tabular}

$326 \quad$ Mothers' educational status

Primary school 116

$116 \quad 25.5$

Junior high school

Senior high school

65
180

14.3

University

Mothers' occupation

Housewife

Worker

Officer

Mothers' occupational status

Employed

Not employed

Family type

Nuclear

Extended

Fragmented

Family's socioeconomic status

Income less than expenses

Income equal to expenses

Income more than expenses

The number of children in the family

1

2

$\geq 3$

55.2

Gender of the babies

Female 251

Male

Baby's age (months)

$0-6$

$7-12$

Delivery type

Natural birth

Caesarean birth

Table 1.

Descriptive

characteristics of the mothers and

babies $(N=455)$
Feeding method

Breast milk $\quad 242$

Formula

Breast milk + formula
274

3.5

197

higher than those whose income is equal to their expenses. It was determined that the number of children had an effect on the unsafe practice of using loose sheets. An increase in the number of children owned increases the risk of an unsafe application by 1.519 times. The family type was found to influence pillow use. The rate of unsafe practices of those who had 


\begin{tabular}{|c|c|c|c|}
\hline Practices & $n$ & $\%$ & Creating \\
\hline $\begin{array}{l}\text { Room sharing } \\
\text { Yes } \\
\text { No }\end{array}$ & $\begin{array}{r}434 \\
21\end{array}$ & $\begin{array}{r}95.4 \\
4.6\end{array}$ & environment \\
\hline $\begin{array}{l}\text { Bed-sharing } \\
\text { Yes } \\
\text { No }\end{array}$ & $\begin{array}{r}31 \\
424\end{array}$ & $\begin{array}{r}6.8 \\
93.2\end{array}$ & 327 \\
\hline $\begin{array}{l}\text { Sleep surfacelfeatur } \\
\text { Firm } \\
\text { Soft }\end{array}$ & $\begin{array}{r}35 \\
420\end{array}$ & $\begin{array}{r}7.7 \\
92.3\end{array}$ & \\
\hline $\begin{array}{l}\text { The way the sheet } \\
\text { Tight } \\
\text { Loose }\end{array}$ & $\begin{array}{r}390 \\
65\end{array}$ & $\begin{array}{l}85.7 \\
14.3\end{array}$ & \\
\hline $\begin{array}{l}\text { Pillow use } \\
\text { Yes } \\
\text { No }\end{array}$ & $\begin{array}{r}396 \\
59\end{array}$ & $\begin{array}{l}87.0 \\
13.0\end{array}$ & \\
\hline $\begin{array}{l}\text { Covering the baby's } \\
\text { Yes } \\
\text { No }\end{array}$ & $\begin{array}{r}77 \\
378\end{array}$ & $\begin{array}{l}16.9 \\
83.1\end{array}$ & \\
\hline $\begin{array}{l}\text { Baby's frequent slee } \\
\text { Supine position } \\
\text { Prone position } \\
\text { Lateral position }\end{array}$ & $\begin{array}{r}168 \\
81 \\
206\end{array}$ & $\begin{array}{l}36.9 \\
17.8 \\
45.3\end{array}$ & \\
\hline $\begin{array}{l}\text { Smoking in the bab } \\
\text { Yes } \\
\text { No }\end{array}$ & $\begin{array}{r}11 \\
444\end{array}$ & $\begin{array}{r}2.4 \\
97.6\end{array}$ & \\
\hline $\begin{array}{l}\text { Using a pacifier wh } \\
\text { Yes } \\
\text { No }\end{array}$ & $\begin{array}{l}304 \\
151\end{array}$ & $\begin{array}{l}66.8 \\
33.2\end{array}$ & \\
\hline $\begin{array}{l}\text { Swaddling } \\
\text { Yes } \\
\text { No }\end{array}$ & $\begin{array}{r}15 \\
440\end{array}$ & $\begin{array}{r}3.3 \\
96.7\end{array}$ & \\
\hline $\begin{array}{l}\text { Temperature of the } \\
\text { Cool }\left(18^{\circ} \mathrm{C}\right) \\
\text { Normal }\left(22-24^{\circ} \mathrm{C}\right) \\
\text { Hot }\left(>24^{\circ} \mathrm{C}\right)\end{array}$ & $\begin{array}{r}4 \\
449 \\
2\end{array}$ & $\begin{array}{r}0.9 \\
98.7 \\
0.4\end{array}$ & $\begin{array}{r}\text { Table } 2 . \\
\text { Practices performed by } \\
\text { mothers to create a safe } \\
\text { sleep } \\
\text { environment }(N=455)\end{array}$ \\
\hline
\end{tabular}

extended families was 3.105 times higher than those who lived as a nuclear family. Those with a fragmented family type were similar to those with a nuclear family type.

Mothers' occupational status was effective on the application of covering the baby's face while sleeping. The misapplication risk of unemployed mothers was 2.262 times higher than that of employed mothers. It has been determined that the number of children and socioeconomic status affected smoking in the baby's sleeping environment. An increase in the number of children increased the risky application rate by 1.924 times. The rate of making risky applications was 9.615 times higher for those whose income was less than their expenses. 
JHR

36,2

\begin{tabular}{|c|c|c|c|c|c|c|c|}
\hline & & & & & & $95 \% \mathrm{CI}$ & for $\exp (\beta)$ \\
\hline & $\beta$ & $\mathrm{SE}$ & Wald statistics & $p$ & $\operatorname{Exp}(\beta)$ & Lower & Upper \\
\hline Bed-sharing & & & & & & & \\
\hline Constant & 3.153 & 0.264 & 142.986 & $<0.001$ & 0.043 & - & - \\
\hline Socioeconomic status & & & & & & & \\
\hline Income equal to expenses & 1 & & & & & & \\
\hline Income less than expenses & 1.635 & 0.382 & 18.343 & $<0.001$ & 5.129 & 2.427 & 10.838 \\
\hline Smoking in the baby's sleep enve & onment & & & & & & \\
\hline Constant & -6.150 & 0.825 & 55.561 & $<0.001$ & 0.002 & - & - \\
\hline The number of children & 0.654 & 0.235 & 7.723 & 0.005 & 1.924 & 1.213 & 3.052 \\
\hline Socioeconomic status & & & & & & & \\
\hline Income equal to expenses & 1 & & & & & & \\
\hline Income less than expenses & 2.263 & 0.705 & 10.309 & 0.001 & 9.615 & 2.415 & 38.280 \\
\hline $\begin{array}{l}\text { The way the sheet is placed } \\
\text { Constant }\end{array}$ & & & & & & & - \\
\hline The number of children & 0.418 & 0.118 & 12.622 & $<0.001$ & 1.519 & 1.206 & 1.913 \\
\hline Pillow use & & & & & & & \\
\hline Constant & 1.757 & 0.147 & 142.208 & $<0.001$ & 5.796 & - & - \\
\hline Family type & & & & & & & \\
\hline Nuclear & 1 & & & & & & \\
\hline Extended & 1.133 & 0.534 & 4.496 & 0.034 & 3.105 & 1.089 & 8.852 \\
\hline Fragmented & 0.641 & 1.055 & 0.369 & 0.544 & 1.898 & 0.240 & 15.000 \\
\hline Covering the baby's face with a & ece of thi & cloth & & & & & \\
\hline Constant & -2.214 & 0.292 & 57.457 & $<0.001$ & 0.109 & & \\
\hline Occupational status employed & 1 & & & & & & \\
\hline Not employed & 0.816 & 0.324 & 6.356 & 0.012 & 2.262 & 1.199 & 4.266 \\
\hline Sleeping position & & & & & & & \\
\hline Constant & -2.398 & 1.044 & 5.271 & 0.022 & 0.091 & & \\
\hline Family type & & & & & & & \\
\hline Fragmented & 1 & & & & & & \\
\hline Nuclear & 3.059 & 1.050 & 8.481 & 0.004 & 21.296 & 2.718 & 166.832 \\
\hline Extended & 2.716 & 1.070 & 6.445 & 0.011 & 15.125 & 1.857 & 123.162 \\
\hline
\end{tabular}

\section{Discussion}

Providing the safest environment for infants every time they sleep is a global public health priority $[20,21]$. We aimed to determine mothers' practices for establishing a safe sleep environment and related factors in the first year of life. As this is a risky period for sleeprelated deaths among babies, we hoped to raise awareness of risky parent groups and practices.

Safe and unsafe practices performed by mothers

The AAP reported that sharing the same room with the baby without sharing the same bed prevents SIDS [17]. The rate of sharing the same room with the baby was quite high $(95.4 \%)$ compared with the study of Özbörü Aşkan et al. [22] at 88\%.

In the present study, the rate of sharing the same bed with the baby was $6.8 \%$. Bedsharing increases the risk of sudden infant deaths [17, 23]. A study by Erdoğan [15] revealed that $28.5 \%$ of the mothers shared the same bed with the baby while they were sleeping $\mathrm{A}$ 
study by Cunningham et al. [21] reported a rate of $44.7 \%$, Stromberg Celind et al. [24] at $44.2 \%$ and Bombard et al. [25] at $61.4 \%$. In a study by Cunningham et al. [21], one factor causing the mothers to share the bed was breastfeeding. A study conducted in the USA reported that bedsharing could not be prevented. It revealed that $55 \%$ of the mothers breastfed their babies at night in a breastfeeding chair, chair or couch, and that $44 \%$ of them fell asleep while breastfeeding in bed [26]. The AAP recommends that the baby may be allowed to sleep in a bed for a while if the baby is taken to bed for breastfeeding and has slept while breastfeeding, but it should be put back in the cradle while the mother is asleep [17]. In our study, the rate of bed-sharing was lower than in other relevant studies, which can be explained by the effectiveness of the training provided. It is recommended that reasons for mothers' sharing beds with their babies should be investigated in future studies.

Having a baby sleep on a soft sleep surface/mattress, not keeping the sheets tight, using soft objects and covering the baby's face with a piece of cloth increase the risk of SIDS due to suffocation [17]. In this study, almost all the mothers slept their babies on soft mattresses. Mathews et al. [27] reported that $72.9 \%$ of the mothers preferred soft mattresses for their babies, and Bombard et al. [25] found that 38.5\% of the mothers used soft mattresses. However, contrary to the aforementioned findings, $54.1 \%$ of the mothers had their babies sleep on firm mattresses in Canbal's study [20]. It was thought that mothers preferred soft mattresses, because they may have thought that their babies would be more comfortable. However, the reasons can be a topic of investigation in another study.

In this study, $16.9 \%$ of the mothers covered their baby's face with a piece of thin cloth during sleeping, compared with $52.3 \%$ in Canbal's study [20]. In Turkish society, traditionally, the baby's face is covered with a piece of thin cloth due to the false belief that it can prevent the baby from developing jaundice [28]. Because such practices could put the baby's sleep safety at risk and lead to suffocation, identification of such traditional false beliefs could be a topic of future studies.

Keeping soft objects such as toys, blankets and pillows in the sleep environment is not recommended because of the risk of airway obstruction in the baby [17]. In this study, most mothers used pillows. Gaw et al. [29] reported that pillows were the most common objects leading to accidental suffocation in infants. Erdoğan [15] revealed that $65.8 \%$ of the mothers placed a pillow under the baby's head, whereas Özbörü Aşkan et al. [22] reported that half of the mothers placed a pillow under the baby's head while their babies were sleeping during the first six months. In Erdoğan and Turan's study [16], 63\% of the mothers placed a pillow under the baby's head.

Although most parents are aware that sleep in the supine position is the safest sleep position, only a few of them had their babies sleep in the correct position [30]. Only one-third of the mothers preferred the supine sleeping position for their babies, and the lateral position was the most preferred. Studies conducted in different countries revealed that the ventral/ lateral position was preferred by $82.1 \%$ of the participants in Brazil, while the supine position/ lying on their back was preferred by $72.4 \%$ in The Netherlands, and $89 \%$ in Georgia $[7,31,32]$. Similar to these findings, $77.3 \%$ of the mothers preferred the supine sleep position in Colson et al.'s study [33].

Some methods can be used to calm the baby. In our study, more than half of the mothers gave pacifiers to their babies to put them to sleep. Our result was consistent with the rate reported by Ozbörü Aşkan et al. at 55.8\% [22]. In this study 3.3\% of mothers swaddled their babies. Swaddling or wrapping is considered a common and traditional practice for settling and soothing the infant. Swaddling or wrapping the infant in a light blanket is often used as a strategy to calm the infant and encourage sleep in the supine position. There is a high risk of death if a swaddled infant is placed in or rolled to the prone position. However, mothers must ensure that the baby is always on his or her back when swaddled. The swaddle should not be too tight or made too hard

\section{Creating \\ a safe sleep environment}

329 
JHR

36,2

for the baby to breathe or move his or her hips [17]. In Cunningham et al.'s study [21], 77.2\% of the mothers responded "yes" to the question "Do you usually wrap your baby?"

In terms of sleep safety, some situations require attention in the environment where the baby sleeps [17]. In this study, almost all the mothers kept the temperature of the room where their babies slept at normal $\left(20-24^{\circ} \mathrm{C}\right)$. It is stated that overheating the baby puts it at risk of SIDS; therefore, the baby should be allowed to sleep at normal room temperature, and excessive clothing should be avoided [17]. In this study, $2.4 \%$ of mothers reported that they smoked cigarettes in the baby's sleep environment, which is an unsafe practice. One of the risk factors for SIDS is smoking in the house in which the infant lives. In Erdoğan's study [15], the proportion of smoking in the house in which the infant lived was $40.8 \%$.

\section{The effect of the sociodemographic characteristics on the mothers' unsafe practices}

It was determined that the socioeconomic status affects bed-sharing practice $(p<0.05)$. Bed-sharing was common in the participants who had low income. In Canbal's study [20], the bed-sharing rate was higher in mothers whose income was lower than their expenses than in other mothers. This finding was consistent with that of our study. Furthermore, sociodemographic factors did not have a significant effect on the characteristic of the mattress used in the baby's sleeping environment $(p>0.05)$. Contrary to the findings of our study, Alparslan and Uçan [34]. found that the rate of laying babies on the soft bed surface significantly increased in large families.

It has been observed that the number of children in the household affects the child's use of loose bedsheets from unsafe practices in the environment where the baby is sleeping and this risk increases as the number of children increases. It was thought that the reasons for the increase in the number of children and the rate of using soft sheets were the increasing care burden. The family type was found to have an effect on pillow use. The risky application is 3.105 times higher for those with extended families than those with nuclear families. In the study of Erdoğan [15], it was found that mothers with an extended family structure were more likely to use pillows to put their babies to sleep. It is thought that this situation is because traditional practices of family elders influenced mothers with an extended family structure in the care of their babies. Similar to our findings, in another study on the subject, there was a relationship between pillow use and family type, and also income level [20].

It has been determined that the number of children and socioeconomic status had an effect on smoking in the baby's sleeping environment. An increase in the number of children in the family increases the risk of misapplication by 1.924 times. The misapplication risk of those whose income was less than their expenses was 9.615 times higher than the reference group. In contrast to our findings, Alparslan and Uçan [34] found no relationship between the baby's exposure to passive cigarette smoke and demographic characteristics .

In this study, it was determined that mothers' occupational status on the application of covering the baby's face while sleeping had an effect, and that unemployed mothers had a higher risk for unsafe application than employed mothers. This may be due to the low education level of most unemployed mothers. Other sociodemographic characteristics were found to have no effect. In Erdoğan's study [15], the rate of the application of covering the baby's face was highest in mothers who were primary school graduates and lowest in university graduates. Alparslan and Uçan [34] found that sociodemographic characteristics were not determinative in covering the baby's face. Meanwhile, Canbal's study [20] reported that the same practice was most frequently performed by mothers under the age of 20 years and least frequently by mothers with a core family and high income.

One of the leading risk factors that increases the possibility of SIDS is the sleep position, although it is a preventable risk factor [17]. In this study, it was determined that only family 
type affects the risky practice of laying the baby in the prone position, which is one of the unsafe practices related to sleeping position. In a study conducted on the same issue, mothers having a core family preferred sleeping their babies in the lateral position [15]. Other sociodemographic characteristics were found to have no effect. Contrary to our findings; Cesar et al. [31] found that the lower the schooling of the mothers and the greater the number of people per bedroom and number of children, the greater the probability of women choosing an unsafe baby sleeping position. Colson et al. [33] found that babies of mothers who did not complete high school were more likely to use the prone position.

Limitations of the study. The results of the study apply only to the mothers who had 0-12month-old babies registered with FHCs in Yozgat city center and are limited to the responses given to the questionnaires by these mothers.

Conclusion. It was determined that mothers applied unsafe practices such as sharing a bed with their baby, having the baby sleep on a soft mattress, using pillows, covering the baby's face with a piece of thin cloth during sleep, smoking in the baby's sleep environment and sleeping the baby in a prone position. It was determined that the factors affecting the unsafe practices of mothers were the number of children, family type, working status and socioeconomic status.

It is recommended that nurses should provide information on creating a safe sleep environment to mothers during prenatal pregnancy follow-ups, during their stay in postnatal maternity services or neonatal units and especially during their visits to FHCs in terms of preventing the risk factors of SIDS because they are most eager to get information during these periods. In addition, risky groups should be identified through home visits; babies' sleep environments should be evaluated, and attempts to prevent risky practices should be made through repeated training. Future research can focus on the further exploration of mothers' beliefs, knowledge and practices regarding risk-reduction recommendations and the impact of cultural practices to create a safe sleeping environment.

\section{Conflict of Interest: None}

\section{References}

1. Moon RY, Task force on sudden infant death syndrome. SIDS and other sleep-related infant deaths: evidence base for 2016 updated recommendations for a safe infant sleeping environment. Pediatrics. 2016; 138(5): e20162940. doi: 10.1542/peds.2016-2940.

2. Aliefendioğlu D, Güzoğlu N. Sudden death of a baby. Turk J Clin Lab. 2016; 7(3): 111-6. (in Turkish).

3. Peacock NR, Altfeld S, Rosenthal AL, Garland CE, Massino JM, Smith SL, et al. Qualitative analysis of infant safe sleep public campaign messaging. Health Promot Pract. 2018; 19(2): 203-12. doi: 10.1177/1524839917690339.

4. Centers for Disease Control and Prevention [CDC]. Sudden unexpected infant death and sudden infant death syndrome: about SUID and SIDS. [cited 2019 April 4]. Available from: https://www. cdc.gov/sids/about/index.htm.

5. Hwang SS, Corwin MJ. Safe infant sleep practices: parental engagement, education, and behavior change. Pediatr Ann. 2017; 46(8): e291-6. doi: 10.3928/19382359-20170719-02.

6. Goodstein MH, Lagon E, Bell T, Joyner BL, Moon RY. Stock photographs do not comply with infant safe sleep guidelines. Clin Pediatr (Phila). 2018; 57(4): 403-9. doi: 10.1177/0009922817728698.

7. Walcott RL, Salm Ward TC, Ingels JB, Llewellyn NA, Miller TJ, Corso PS. A statewide hospitalbased safe infant sleep initiative: measurement of parental knowledge and behavior. J Community Health. 2018; 43(3): 534-42. doi: 10.1007/s10900-017-0449-x.

8. Centers for Disease Control and Prevention [CDC]. Sudden unexpected infant death and sudden infant death syndrome: breakdown of sudden unexpected infant deaths by cause, 2018. [cited 2020 November 9]. Available from: https://www.cdc.gov/sids/data.htm\#pie.

\section{Creating \\ a safe sleep environment}


JHR

36,2

332
9. Dolar O, Gökçay G, Bulut A, Neyzi O. Epidemiology of under five mortality in Istanbul: changes from 1988 to 2000. Nufusbil Derg. 2005; 27(1): 35-48. (in Turkish).

10. Çelik T, Altun AB, Kerkez B, Tatlı S, Özer C. The infant mortality rates and its causes in Hatay province during the years 2009 and 2010. Ege J Med. 2012; 51(2): 111-6. (in Turkish).

11. Yildiz S, Özdemir ME, Benli AR. Investigation of causes of infant death in Kayseri province in 2017. Turk J Family Med Prim Care. 2020; 14(2): 196-202. doi: 10.21763/tjfmpc.630448 (in Turkish).

12. Hirshkowitz M, Whiton K, Albert SM, Alessi C, Bruni O, DonCarlos L, et al. National Sleep Foundation's updated sleep duration recommendations: final report. Sleep Health. 2015; 1(4): 233-43. doi: 10.1016/j.sleh.2015.10.004.

13. Paruthi S, Brooks LJ, D’Ambrosio C, Hall WA, Kotagal S, Lloyd RM, et al. Recommended amount of sleep for pediatric populations: a consensus statement of the American academy of sleep medicine. J Clin Sleep Med. 2016; 12(6): 785-6. doi: 10.5664/jcsm.5866.

14. Heere M, Moughan B, Alfonsi J, Rodriguez J, Aronoff S. Effect of education and cardboard bassinet distribution on newborn bed-sharing. Glob Pediatr Health. 2019; 6: $2333794 X 19829173$. doi: 10.1177/2333794X19829173.

15. Erdoğan Ç. Determining maternal behaviors that put infants between 0-12 months at risk of sudden infant death syndrome in the city of Denizli. Pamukkale, Denizli: Pamukkale University; 2015. (in Turkish).

16. Erdoğan Ç, Turan T. Mothers' preferences for safe sleep in newborns. J Turk Sleep Med. 2018; 5(3): 58-61. doi: 10.4274/jtsm.25743. (in Turkish).

17. American Academy of Pediatrics [AAP]. Task Force on Sudden Infant Death Syndrome. SIDS and other sleep-related infant deaths: updated 2016 recommendations for a safe infant sleeping environment. Pediatrics. 2016; 138(5): e20162938. doi: 10.1542/peds.2016-2938.

18. Hitchcock SC. An update on safe infant sleep. Nurs Womens Health. 2017; 21(4): 307-11. doi: 10. 1016/j.nwh.2017.06.007.

19. Whiteside-Mansell L, Nabaweesi R, Caballero AR, Mullins SH, Miller BK, Aitken ME. Assessment of safe sleep: validation of the parent newborn sleep safety survey. J Pediatr Nurs. 2017; 35: 30-5. doi: 10.1016/j.pedn.2017.02.033.

20. Canbal S. Evaluation of the knowledge and attitudes of mothers with 0-1 year-old babies about the risk factors of sudden infant death syndrome. Gaziantep: Hasan Kalyoncu University; 2018. (in Turkish).

21. Cunningham HM, Vally H, Bugeja L. Bed-sharing in the first 8 weeks of life: an Australian study. Matern Child Health J. 2018; 22(4): 556-64. doi: 10.1007/s10995-017-2424-7.

22. Özbörü Aşkan Ö, Keskindemirci G, Kilic A, Gökçay G. Evaluation of sleep safety in infants: preliminary results of the pilot study. J Child. 2018; 18(3): 135-9. doi: 10.5222/j.child.2018.63307 (in Turkish).

23. Fleming P, Pease A, Blair P. Bed-sharing and unexpected infant deaths: what is the relationship? Paediatr Respir Rev. 2015; 16(1): 62-7. doi: 10.1016/j.prrv.2014.10.008.

24. Stromberg Celind F, Wennergren G, Mollborg P, Goksor E, Alm B. Area-based study shows most parents follow advice to reduce risk of sudden infant death syndrome. Acta Paediatr. 2017; 106(4): 579-85. doi: 10.1111/apa.13711.

25. Bombard JM, Kortsmit K, Warner L, Shapiro-Mendoza CK, Cox S, Kroelinger CD, et al. Vital signs: trends and disparities in infant safe sleep practices - United States, 2009-2015. MMWR Morb Mortal Wkly Rep. 2018; 67(1): 39-46. doi: 10.15585/mmwr.mm6701e1.

26. Kendall-Tackett K, Cong Z, Hale TW. Mother-infant sleep locations and nighttime feeding behavior: U.S. data from the survey of mothers' sleep and fatigue. Clin Lactation. 2010; 1(1): 27-31. doi: 10.1891/215805310807011837. 
27. Mathews A, Oden R, Joyner B, He J, McCarter R, Moon RY. Differences in African-American maternal self-efficacy regarding practices impacting risk for sudden infant death. J Community Health. 2016; 41(2): 244-9. doi: 10.1007/s10900-015-0088-z.

28. Yiğitalp G, Gümüş F. Traditional infant care practices of women aged 15-49 in Diyarbakir. Turk J Pediatr Dis. 2017; 3: 188-96. doi: 10.12956/tjpd.2017.266. (in Turkish).

29. Gaw CE, Chounthirath T, Midgett J, Quinlan K, Smith GA. Types of objects in the sleep environment associated with infant suffocation and strangulation. Acad Pediatr. 2017; 17(8): 893-901. doi: 10.1016/j.acap.2017.07.002.

30. Naugler MR, DiCarlo K. Barriers to and interventions that increase nurses' and parents' compliance with safe sleep recommendations for preterm infants. Nurs Womens Health. 2018; 22(1): 24-39. doi: 10.1016/j.nwh.2017.12.009.

31. Cesar JA, Marmitt LP, Carpena MX, Pereira FG, Neto JDM, Neumann NA, et al. Maternal knowledge and unsafe baby sleep position: a cross-sectional survey in Southern Brazil. Matern Child Health J. 2019; 23(2): 183-90. doi: 10.1007/s10995-018-2613-z.

32. Konijnendijk AAJ, Engelberts AC, L'Hoir MP, Boere-Boonekamp MM. Eleventh safe sleeping survey in The Netherlands: parents' habits concerning infant sleep position and location. Ned Tijdschr Geneeskd. 2018; 162: D2366. (in Dutch).

33. Colson ER, Geller NL, Heeren T, Corwin MJ. Factors associated with choice of infant sleep position. Pediatrics. 2017; 140(3): e20170596. doi: 10.1542/peds.2017-0596.

34. Alparslan Ö, Uçan S. Determination of risk factors related to sudden infant death syndrome in infants in a health centre region. Turk J Res Dev Nurs. 2011; 13(1): 25-34. (in Turkish).

\section{Corresponding author}

Ayşe Şener Taplak can be contacted at: hem.ayse_3886@hotmail.com
Creating

a safe sleep environment

For instructions on how to order reprints of this article, please visit our website:

www.emeraldgrouppublishing.com/licensing/reprints.htm

Or contact us for further details: permissions@emeraldinsight.com 